\title{
Vitiligo and Autoimmune Thyroid Disorders
}

\begin{abstract}
Enke Baldini ${ }^{1}$, Teresa Odorisio ${ }^{2}$, Salvatore Sorrenti', Antonio Catania', Francesco Tartaglia', Giovanni Carbotta ${ }^{1}$, Daniele Pironi', Roberta Rendina ${ }^{3}$, Eleonora D'Armiento ${ }^{3}$, Severino Persechino ${ }^{4}$ and Salvatore Ulisse ${ }^{1 *}$
\end{abstract}

'Department of Surgical Sciences, "Sapienza" University of Rome, Rome, Italy, ${ }^{2}$ Laboratory of Molecular and Cell Biology, Istituto Dermopatico dell'Immacolata-IRCCS, Rome, Italy, ${ }^{3}$ Department of Internal Medicine and Medical Specialties, "Sapienza" University of Rome, Rome, Italy, ${ }^{4}$ NESMOS Department, "Sapienza" University of Rome, Rome, Italy

Vitiligo represents the most common cause of acquired skin, hair, and oral depigmentation, affecting $0.5-1 \%$ of the population worldwide. It is clinically characterized by the appearance of disfiguring circumscribed skin macules following melanocyte destruction by autoreactive cytotoxic T lymphocytes. Patients affected by vitiligo usually show a poorer quality of life and are more likely to suffer from depressive symptoms, particularly
OPEN ACCESS

Edited by: Alessandro Antonelli, University of Pisa, Italy

Reviewed by: Ilaria Ruffilli,

University of Pisa, Italy Silvia Martina Ferrari,

University of Pisa, Italy

Salvatore Benvenga, University of Messina, Italy Flavia Di Bari,

Policlinico di Messina, Italy

*Correspondence:

Salvatore Ulisse salvatore.ulisse@uniroma1.it

Specialty section: This article was submitted to Thyroid Endocrinology,

a section of the journal

Frontiers in Endocrinology

Received: 19 July 2017 Accepted: 11 October 2017 Published: 27 October 2017

Citation:

Baldini E, Odorisio T, Sorrenti S, Catania A, Tartaglia F, Carbotta G, Pironi D, Rendina R, D'Armiento $E$,

Persechino S and Ulisse S (2017)

Vitiligo and Autoimmune Thyroid Disorders.

Front. Endocrinol. 8:290. doi: 10.3389/fendo.2017.00290 evident in dark-skinned individuals. Although vitiligo is a non-fatal disease, exposure of affected skin to UV light increases the chance of skin irritation and predisposes to skin cancer. In addition, vitiligo has been associated with other rare systemic disorders due to the presence of melanocytes in other body districts, such as in eyes, auditory, nervous, and cardiac tissues, where melanocytes are thought to have roles different from that played in the skin. Several pathogenetic models have been proposed to explain vitiligo onset and progression, but clinical and experimental findings point mainly to the autoimmune hypothesis as the most qualified one. In this context, it is of relevance the strong association of vitiligo with other autoimmune diseases, in particular with autoimmune thyroid disorders, such as Hashimoto thyroiditis and Graves' disease. In this review, after a brief overview of vitiligo and its pathogenesis, we will describe the clinical association between vitiligo and autoimmune thyroid disorders and discuss the possible underlying molecular mechanism(s).

Keywords: vitiligo, autoimmune thyroid diseases, tyrosinase, TSH receptor, thyroglobulin, reactive oxygen species, $\mathrm{CD}^{+} \mathrm{T}$ cells, autoimmune polyendocrine syndromes

\section{VITILIGO: AN OVERVIEW}

Vitiligo represents the most common cause of acquired skin, hair and oral depigmentation, and often occurs as an inherited disease (1). Clinically, it is characterized by the progressive loss of melanocytes causing the appearance of well-circumscribed milky/white cutaneous macules. Histologically, skin lesions show basal hypopigmentation and increased dermal inflammation relative to perilesional normal skin, with complete or near-complete loss of melanocytes at the basal epidermal layer (2). Following the Vitiligo Global Issues Consensus Conference in 2011, the disease has been categorized based on clinical parameters into: segmental vitiligo (SV), non-segmental vitiligo (NSV), and mixed vitiligo (MV) (1). SV is characterized by a unilateral distribution of the macules and is less common compared with the NSV, which shows symmetrical and bilateral white patches (3). NSV includes different clinical vitiligo subtypes, namely, acrofacial, generalized, mucosal, and universal vitiligo. NSV may be initially classified as acrofacial and, over time, be reclassified as generalized or universal 
vitiligo. On the other hand, MV includes the combination of an initial SV followed by the occurrence, after several months or years, of bilateral NSV patches $(1,4)$.

The prevalence of vitiligo has been estimated to be $0.5-1 \%$ of the world population. However, it can vary from country to country. In fact, the prevalence recorded in Denmark is $0.38 \%$, whereas in India it is up to $8.8 \%(1,5,6)$. Vitiligo can arise at any age, even if about $50 \%$ of cases are diagnosed before the age of 20 , and both sexes are equally affected $(1,6)$.

Due to its disfiguring effects, vitiligo may have a detrimental impact on patient's quality of life (QoL) and mental health (7-9). A recent review of studies published over the last two decades indicates that women show more QoL impairment than men, married women more than singles, young patients more than elderly ones, and dark-skinned people more than white people $(7,8)$. Moreover, a recent meta-analysis demonstrated that vitiligo patients were significantly more likely to suffer from depression (9). Although vitiligo is a non-fatal disease, exposure of affected skin to UV light increases the chance of skin irritation and cancer (10). Furthermore, vitiligo has been associated with other rare systemic disorders, including the Vogt-Koyanagi-Harada, the Kabuki, and mitochondrial encephalopathy, lactic acidosis, and stroke-like episodes (MELAS) syndromes due to the presence of melanocytes in other parts of the body, such as in eyes, auditory, nervous, and cardiac tissues, where melanocytes are thought to have different roles from that played in the skin (11). In particular, the Vogt-Koyanagi-Harada disease is an autoimmune multisystemic disorder branded by granulomatous panuveitis with exudative retinal detachments, neurologic and hearing manifestations, and vitiligo. The Kabuki syndrome manifests with abnormalities in multiple organ systems and is characterized by distinctive facial features, including arched eyebrows, long eyelashes, long openings of the eyelids with the everted lower lids, and large protruding earlobes. It usually associates with autoimmune diseases such as idiopathic thrombocytopenic purpura, hemolytic anemia, thyroiditis, and vitiligo. The MELAS syndrome is a mitochondrial disorder due to mutations of the mitochondrial genome. The typical presentation of patients with MELAS syndrome is described by the name of the disorder. Additional features are seizures, diabetes mellitus, hearing loss, cardiac disease, short stature, endocrinopathies, neuropsychiatric dysfunctions and skin alterations including hypertrichosis, eczema, and vitiligo.

\section{PATHOGENESIS}

Although several hypotheses have been put forward to explain vitiligo ethiopathogenesis, the autoimmune theory is the most accredited one, being sustained by several epidemiological, clinical, and experimental findings (4, 9, 11-17). These studies indicate that melanocyte defects drive vitiligo pathogenesis by triggering, in susceptible individuals, an autoimmune response that leads to melanocyte destruction (11). Several exogenous and endogenous stimuli have been linked to the onset of the disease. The exogenous factors include ultraviolet irradiations, trauma (Koebner phenomenon), stress, major infections, malignancies, neural abnormalities, vaccinations, pregnancy, calcium imbalance, certain drugs, hormones, and exposure to cytotoxic compounds. Among the endogenous factors are melanin synthesis, cellular metabolism, proliferation, differentiation, apoptosis, and immune reactions $(11,14,18-20)$. All of these are thought to induce oxidative stress in melanocytes, as indicated by the high levels of reactive oxygen species (ROS), mainly hydrogen peroxide and peroxinitrite, found in lesional skin (11, 14, 18-20). The ROS increase may also result from compromised antioxidant responses with local and/or systemic imbalance of the antioxidant systems $(11,14,18-20)$. For example, the superoxide dismutase is present at higher levels in perilesional skin and patient's sera $(17,20)$, whereas the level of the antioxidant enzyme catalase was found reduced in the vitiliginous skin compared with normal skin (20). The important role played by the antioxidant system in the pathogenesis of vitiligo is further corroborated by a recent study showing the association between a single nucleotide polymorphism of the nuclear factor, erythroid 2 like 2 (NRF2) gene and vitiligo $(19,21)$. The transcription factor Nrf2 regulates genes containing the antioxidant response elements (AREs) in their promoters and encoding proteins that protect against oxidative damage triggered by injury and inflammation. In addition, it has been shown that Nfr2-ARE/heme oxygenase-1 pathway is functionally deficient in the disease-free epidermis of patients with vitiligo (22). This is in agreement with very recent findings showing the ability of simvastatin to protect human melanocytes from $\mathrm{H}_{2} \mathrm{O}_{2}$-induced oxidative stress by activating Nrf2 (23). Finally, reduced levels of non-enzymatic antioxidants such as beta-carotene, ubiquinone, vitamins $\mathrm{E}$ and $\mathrm{C}$, ferritin, and metallothionein may contribute to the increased amount of ROS observed in vitiliginous melanocytes (19).

Oxidative stress may affect the structure and functions of the endoplasmic reticulum (ER), which act as a cellular stress sensor. Dilation of the ER is a hallmark of melanocytes at the periphery of vitiligo lesions, and the disruption of redox reactions, critical for proper protein folding, causes the accumulation of immature proteins and misfolded peptides leading to the activation of the unfolded protein response (UPR) $(24,25)$. The latter, under sustained cellular stress, promotes autoimmune responses via apoptotic cascades (19). Actually, exposure to chemical triggers of vitiligo was shown to induce oxidative stress and to promote UPR activation in melanocytes (26). The importance of the UPR in the pathogenesis of vitiligo is further corroborated by several lines of experimental evidence, which identified the X-box binding protein 1 (XBP1) gene, encoding a transcription factor mediating UPR activation, as a susceptibility locus for generalized vitiligo (27-30). The UPR induces also the expression of cytokines, such as IL-6, IL-8, IL-11, and tumor necrosis factor, and can attract cells of the innate immune system to the skin of vitiligo patients, as documented by the aberrant activation of natural killer and dendritic cells (DCs) in lesional skin (11). More recently, a role for calreticulin (CRT), an ER protein regulating intracellular $\mathrm{Ca}^{2+}$, has been proposed in the progression of vitiligo (19). In particular, a redistribution of CRT from the ER lumen to the plasma membrane of melanocytes takes place under oxidative stress (19). Surface CRT is thought to direct the contact of stressed melanocytes with DCs, eliciting downstream immune responses and melanocyte apoptosis. The latter provides 
abundant antigenic peptides to the antigen-presenting cells leading to the activation of $\mathrm{T}$ cells, thus promoting autoimmunity. In this context, it is also worth to consider that the increased ROS levels are thought to modify tyrosinase (TYR) and other melanogenic proteins into neoantigens (11). Indeed, patients affected by vitiligo show circulating autoantibodies directed toward specific melanocyte antigens such as TYR, tyrosinaserelated protein-1 (TRP-1), TRP-2, Pmel17 (or gp100), and type 1 membrane receptor for melanin-concentrating hormone, whose serum level correlates with the disease severity $(11,31-36)$. In early lesions, $\mathrm{CD}^{+}$cytotoxic $\mathrm{T}$ lymphocytes have been found close to melanocytes, and a perivascular lymphocytic infiltrate could be appreciated at the expanding edge of active skin lesions (37). In addition, the concentration of melanocyte-specific $\mathrm{CD}^{+} \mathrm{T}$ cells is higher in the blood of patients affected by vitiligo and correlates with disease activity $(11,31,38)$. Furthermore, interferon- $\gamma(\mathrm{IFN}-\gamma)$ has been shown to play a central role in vitiligo progression through the release of several chemokines, such as CXCL9, 10, and $11(17,39)$. It has been also suggested that IFN- $\gamma$ could play a direct role in vitiligo pathogenesis following the observation that the IFN- $\gamma$ derived from cytotoxic $\mathrm{T}$ cells could itself cause apoptosis in melanocytes (40). This is in agreement with recent studies showing that human vitiligo as well as a mouse model of vitiligo reflects an IFN- $\gamma$-specific Th1 immune response in the skin that involves IFN- $\gamma$-dependent chemokines (41-44).

Recent findings indicate the participation in this process of TH17 cells, identified in the lesional skin of vitiligo patients $(45,46)$. The TH17 cells, by releasing interleukin-17, may induce in activated immune cells secretion of proinflammatory cytokines, which in turn recruit and activate mononuclear lymphocytes, strongly involved in disease progression (46). Finally, regulatory $\mathrm{T}$ cells (Treg), which are in charge to maintain peripheral tolerance through the suppression of self-reactive T cells, appear reduced in number and functionally flawed in lesional skin of patients affected by vitiligo (47).

A number of studies have shown that the uptake by keratinocytes of the melanocyte released melanosomes take place through phagocytic ingestion in a receptor-mediated process, involving the protease-activated receptor- 2 and keratinocyte growth factor receptor/fibroblast growth factor receptor $2 \mathrm{~b}$ (KGFR/FGFR2b) (48-50). A recent work reported a decreased expression of KGF/ FGF7 and its receptor in pathological hypopigmented skin, which may contribute to the formation of the classical milky macules of vitiligo (50).

Finally, it is worth to mention that a number of genome-wide association and genetic linkage studies identified more than 30 different genes related to an increased risk of vitiligo, the majority of which are immune genes implicated in both the innate and the adaptive immune responses $(4,9,11,13)$.

\section{ASSOCIATION WITH AUTOIMMUNE THYROID DISEASES (AITD)}

Besides the abovementioned involvement of the immune system in vitiligo pathogenesis, epidemiological evidence further corroborates the autoimmune genesis of vitiligo. In particular, vitiligo is present within the autoimmune polyendocrine syndromes (51), and it is more frequently encountered in family members of patients affected by autoimmune diseases, such as inflammatory bowel disease, psoriasis, rheumatoid arthritis, type 1 diabetes, systemic lupus erythematosus, pernicious anemia, and AITD (31, 52-69). The latter, as outlined in several studies performed over the last decades, represent the most frequent autoimmune disorders associated with vitiligo (54, 58, 66-73). A recent meta-analysis, performed on 48 articles published between 1968 and 2012, showed that in patients affected by vitiligo the prevalence of AITD was $14.3 \%$, while positivity to thyroid-specific antibodies [i.e., anti-thyroglobulin (Tg), anti-thyroid peroxidase, and anti-thyrotropin receptor (TSHR)] was found in $20.8 \%$ of them (74). Moreover, the presence of anti-thyroid hormones antibodies in the serum of patients affected by vitiligo was detected in 77 out of 79 vitiligo patients analyzed, suggesting a possible pathogenetic role $(70,75)$. Vice versa, the prevalence of vitiligo among AITD patients has been reported to vary from 2.7 to $7 \%(66,67,76,77)$. It is also worth to note that the risk of thyroid disease in vitiligo patients increases with age $(71,74)$. All together, these findings have led to the recommendation of screening patients affected by vitiligo for thyroid diseases and thyroid autoantibodies, in an effort to detect undiagnosed thyroid diseases or to assess the risk of future onset $(74,78)$.

\section{MOLECULAR MECHANISMS UNDERLYING VITILIGO AND THYROID AUTOIMMUNE DISEASE ASSOCIATION}

The reported association of vitiligo with AITD suggests the presence of shared heritable susceptibility genes (79-87). Thirty-seven susceptibility genes have been identified for vitiligo disease and more than 15 for AITD (79-87). Genome-wide linkage analysis and candidate gene association studies identified nine loci potentially involved in both AITD and vitiligo (79-81). Among these, there are organ-specific genes such as those coding for TYR, Tg, and TSHR (81-85). In addition, an autoimmunity susceptibility locus (AIS1) was identified by genome-wide linkage analysis on chromosome 1 in families characterized by vitiligo and Hashimoto's thyroiditis (HT) (86-88). Among the 27 genes mapping to the AIS1 locus, the forkhead transcription factor D3 appears to be the most plausible responsible for the concomitant occurrence of vitiligo and AITD $(86,89)$. In addition, a single nucleotide polymorphism of the PTPN22 gene, encoding a lymphoid specific phosphatase, is shared among patients with vitiligo and AITD (79). These findings suggest that the association observed between vitiligo and AITD could be explained, at least in part, by the sharing of a subset of susceptibility genes.

Of interest are the recently reported observations showing melanocyte-specific antigen expression in thyroid tissues of patients with HT, as well as in thyroid tissues of healthy individuals (88). In particular, thyroid tissues from HT patients without vitiligo, and normal thyroid tissues, were both negative for the expression 
of NKI/beteb, Pmel17, TRP-1, HMB-45, and S100, whereas they were positive for the expression of TRP-2, lysosome-associated membrane protein 1 (LAMP1), and CD69. Interestingly, TYR was only detected in thyroid from HT patients. Moreover, levels of LAMP1 and CD69 were higher in thyroid with HT compared with normal thyroid (90). The differences in type and amount of melanocyte antigens observed in the thyroid of HT patients may provide the immunological basis for secondary vitiligo associated with HT. Vice versa, different skin cell types, including keratinocytes, dermal fibroblasts, and melanocytes, have been shown to express functional TSHR and other thyroid-specific antigens including Tg, thyroperoxidase, and natrium/iodide symporter $(91,92)$. Thus, it may be speculated that in vitiligo patients the activation of the immune system against these antigens expressed in vitiliginous melanocytes may cause a secondary AITD.

\section{REFERENCES}

1. Ezzedine K, Lim HW, Suzuki T, Katayama I, Hamzavi I, Lan CC, et al. Vitiligo Global Issue Consensus Conference Panelists. Pigment Cell Melanoma Res (2012) 25:E1-13. doi:10.1111/j.1755-148X.2012.00997.x

2. Ezzedine K, Gauthier Y, Léauté-Labrèze C, Marquez S, Boucht-nei S, Jouary T, et al. Segmental vitiligo associated with generalized vitiligo (mixed vitiligo): a retrospective case series of 19 patients. JAm Acad Dermatol (2011) 65:965-71. doi:10.1016/j.jaad.2010.08.031

3. Behl PN, Bhatia RK. 400 cases of vitiligo. A clinico-therapeutic analysis. Indian J Dermatol (1972) 17:51-6.

4. Ezzedine K, Eleftheriadou V, Whitton M, van Geel N. Vitiligo. Lancet (2015) 386:74-84. doi:10.1016/S0140-6736(14)60763-7

5. Howitz J, Brodthagen H, Schwartz M, Thomsen K. Prevalence of vitiligo. Epidemiological survey on the Isle of Bornholm, Denmark. Arch Dermatol (1977) 113:47-52. doi:10.1001/archderm.1977.01640010049006

6. Amer AA, Gao XH. Quality of life in patients with vitiligo: an analysis of the dermatology life quality index outcome over the past two decades. Int J Dermatol (2016) 55:608-14. doi:10.1111/ijd.13198

7. Pandve HT. Vitiligo: is it just a dermatological disorder? Indian J Dermatol (2008) 53:40-1. doi:10.4103/0019-5154.39745

8. Lai Y, Yew YW, Kennedy C, Schwartz RA. Vitiligo and depression: a systematic review and meta-analysis of observational studies. Br J Dermatol (2016) 177(3):708-18. doi:10.1111/bjd.15199

9. Patel S, Rauf A, Khan H, Meher BR, Hassan SSU. A holistic review on the autoimmune disease vitiligo with emphasis on the casual factors. Biomed Pharmacother (2017) 92:501-8. doi:10.1016/j.biopha.2017.05.095

10. Ahluwalia J, Correa-Selm LM, Rao BK. Vitiligo: not simply a skin disease. Skinmed (2017) 15:125-7.

11. Rodrigues M, Ezzedine K, Hamzavi I, Pandya AG, Harris JE, Vitiligo Working Group. New discoveries in the pathogenesis and classification of vitiligo. J Am Acad Dermatol (2017) 77:1-13. doi:10.1016/j.jaad.2016.10.048

12. Manolache L, Benea V. Stress in patients with alopecia areata and vitiligo. J Eur Acad Dermatol Venereol (2007) 21:921-8. doi:10.1111/j.1468-3083.2006. 02106.x

13. Strassner JP, Harris JE. Understanding mechanisms of autoimmunity through translational research in vitiligo. Curr Opin Immunol (2016) 43:81-8. doi:10.1016/j.coi.2016.09.008

14. Colucci R, Dragoni F, Moretti S. Oxidative stress and immune system in vitiligo and thyroid diseases. Oxid Med Cell Longev (2015) 2015:631927. doi:10.1155/2015/631927

15. Taieb A, Picardo M. Vitiligo. New Engl J Med (2009) 360:160-9. doi:10.1056/ NEJMcp0804388

16. Le Poole IC, Luiten RM. Autoimmune etiology of generalized vitiligo. Curr Dir Autoimmun (2008) 10:227-43. doi:10.1159/000131485

17. Manga P, Elbuluk N, Orlow SJ. Recent advances in understanding vitiligo. F1000Res (2016) 5(F1000 Faculty Rev):2234. doi:10.12688/ f1000research.8976.1

\section{CONCLUSION}

Knowledge regarding the pathogenesis of vitiligo has considerably increased over the last decades starting to clarify the molecular mechanisms underlying disease etiology and progression, as well as the association with other autoimmune disorders. Several susceptibility genes have been identified in both vitiligo and AITD patients that, along with the identification of shared antigens between melanocytes and thyrocytes, may contribute to explain the observed association between AITD and vitiligo.

\section{AUTHOR CONTRIBUTIONS}

All the authors contributed to the first draft of the article and its revision and approved its final version.

18. Picardo M, Bastonini E. A new view of vitiligo: looking at normal-appearing skin. J Invest Dermatol (2015) 135:1713-4. doi:10.1038/jid.2015.92

19. Xie H, Zhou F, Liu L, Zhu G, Li Q, Li C, et al. Vitiligo: how do oxidative stress-induced autoantigens trigger autoimmunity? J Dermatol Sci (2016) 81:3-9. doi:10.1016/j.jdermsci.2015.09.003

20. Sravani PV, Babu NK, Gopal KV, Rao GR, Rao AR, Moorthy B, et al. Determination of oxidative stress in vitiligo by measuring superoxide dismutase and catalase levels in vitiliginous and non-vitiliginous skin. Indian J Dermatol Venereol Leprol (2009) 75:268-71. doi:10.4103/0378-6323.48427

21. Song P, Li K, Liu L, Wang X, Jian Z, Zhang W, et al. Genetic polymorphism of the Nrf2 promoter region is associated with vitiligo risk in Han Chinese populations. J Cell Mol Med (2016) 20:1840-50. doi:10.1111/jcmm.12874

22. Jian Z, Li K, Song P, Zhu G, Zhu L, Cui T, et al. Impaired activation of the Nrf2-ARE signaling pathway undermines $\mathrm{H} 2 \mathrm{O} 2$-induced oxidative stress response: a possible mechanism for melanocyte degeneration in vitiligo. J Invest Dermatol (2014) 134:2221-30. doi:10.1038/jid.2014.152

23. Chang Y, Li S, Guo W, Yang Y, Zhang W, Zhang Q, et al. Simvastatin protects human melanocytes from $\mathrm{H}_{2} \mathrm{O}_{2}$-induced oxidative stress by activating $\mathrm{Nrf2}$. J Invest Dermatol (2017) 137:1286-96. doi:10.1016/j.jid.2017.01.020

24. Boissy RE, Liu YY, Medrano EE, Nordlund JJ. Structural aberration of the rough endoplasmic reticulum and melanosome compartmentalization in long-term cultures of melanocytes from vitiligo patients. J Invest Dermatol (1991) 97:395-404. doi:10.1111/1523-1747.ep12480976

25. Eletto D, Chevet E, Argon Y, Appenzeller-Herzog C. Redox controls UPR to control redox. J Cell Sci (2014) 127:3649-58. doi:10.1242/jcs.153643

26. Toosi S, Orlow S, Manga P. Vitiligo-inducing phenols activate the unfolded protein response in melanocytes resulting in upregulation of IL6 and IL8. J Invest Dermatol (2012) 132:2601-9. doi:10.1038/jid.2012.181

27. Chen JJ, Huang W, Gui JP, Yang S, Zhou FS, Xiong QG, et al. A novel linkage to generalized vitiligo on 4q13-q21 identified in a genome-wide linkage analysis of Chinese families. Am J Hum Genet (2005) 76:1057-65. doi:10.1086/430279

28. Ren Y, Yang S, Xu S, Gao M, Huang W, Gao T, et al. Genetic variation of promoter sequence modulates XBP1 expression and genetic risk for vitiligo. PLoS Genet (2009) 5:e1000523. doi:10.1371/journal.pgen.1000523

29. Birlea SA, Jin Y, Bennett DC, Herbstman DM, Wallace MR, McCormack WT, et al. Comprehensive association analysis of candidate genes for generalized vitiligo supports XBP1, FOXP3, and TSLP. J Invest Dermatol (2011) 131:371-81. doi:10.1038/jid.2010.337

30. Acosta-Alvear D, Zhou Y, Blais A, Tsikitis M, Lents NH, Arias C, et al. XBP1 controls diverse cell type- and condition-specific transcriptional regulatory networks. Mol Cell (2007) 27:53-66. doi:10.1016/j.molcel.2007.06.011

31. Alkhateeb A, Fain PR, Thody A, Bennett DC, Spritz RA. Epidemiology of vitiligo and associated autoimmune diseases in Caucasian probands and their families. Pigement Cell Melanoma Res (2003) 16:208-14. doi:10.1034/j.1600-0749.2003.00032.x

32. Harning R, Cui J, Bystryn J-C. Relation between the incidence and level of pigment cell antibodies and disease activity in vitiligo. J Invest Dermatol (1991) 97:1078-80. doi:10.1111/1523-1747.ep12492607 
33. Uda H, Takei M, Mishima Y. Immunopathology of vitiligo vulgaris, Sutton's leukoderma and melanoma-associated vitiligo in relation to steroid effects. II. The IgG and C3 deposits in the skin. J Cutaneous Pathol (1984) 11:114-24. doi:10.1111/j.1600-0560.1984.tb00361.x

34. Okamoto T, Irie RF, Fujii S, Huang SK, Nizze AJ, Morton DL, et al. Anti-tyrosinase-related protein-2 immune response in vitiligo patients and melanoma patients receiving active-specific immunotherapy. J Invest Dermatol (1998) 111:1034-9. doi:10.1046/j.1523-1747.1998.00411.x

35. Kemp EH, Gawkrodger DJ, Watson PF, Weetman AP. Autoantibodies to human melanocyte-specific protein Pmel17 in the sera of vitiligo patients: a sensitive and quantitative radioimmunoassay (RIA). Clin Exp Immunol (1998) 114:333-8. doi:10.1046/j.1365-2249.1998.00746.x

36. Kemp EH, Waterman EA, Hawes BE, O'Neill K, Gottumukkala RV, Gawkrodger DJ, et al. The melanin-concentrating hormone receptor 1, a novel target of autoantibody responses in vitiligo. J Clin Invest (2002) 109:923-30. doi:10.1172/JCI0214643

37. Le Poole IC, van den Wijngaard RM, Westerhof W, Das PK. Presence of $\mathrm{T}$ cells and macrophages in inflammatory vitiligo skin parallels melanocyte disappearance. Am J Pathol (1996) 148:1219-28.

38. Ogg GS, Rod Dunbar P, Romero P, Chen JL, Cerundolo V. High frequency of skin-homing melanocyte-specific cytotoxic T lymphocytes in autoimmune vitiligo. J Exp Med (1998) 188:1203-8. doi:10.1084/jem.188.6.1203

39. Ferrari SM, Fallahi P, Santaguida G, Virili C, Ruffilli I, Ragusa F, et al. Circulating CXCL10 is increased in non-segmental vitiligo, in presence or absence of autoimmune thyroiditis. Autoimmun Rev (2017) 16(9):946-50. doi:10.1016/j.autrev.2017.07.006

40. Yang L, Wei Y, Sun Y, Shi W, Yang J, Zhu L, et al. Interferon-gamma inhibits melanogenesis and induces apoptosis in melanocytes: a pivotal role of CD8+ cytotoxic T lymphocytes in vitiligo. Acta Derm Venereol (2015) 95:664-70. doi:10.2340/00015555-2080

41. Antonelli A, Ferrari SM, Fallahi P. The role of the Th1 chemokine CXCL10 in vitiligo. Ann Transl Med (2015) 3(Suppl 1):S16. doi:10.3978/j.issn.23055839.2015.03.02

42. Rashighi M, Agarwal P, Richmond JM, Harris TH, Dresser K, Su MW, et al. CXCL10 is critical for the progression and maintenance of depigmentation in a mouse model of vitiligo. Sci Transl Med (2014) 6:223ra23. doi:10.1126/ scitranslmed.3007811

43. Harris JE, Harris TH, Weninger W, Wherry EJ, Hunter CA, Turka LA. A mouse model of vitiligo with focused epidermal depigmentation requires IFN- $\gamma$ for autoreactive CD8+ T-cell accumulation in the skin. J Invest Dermatol (2012) 132:1869-76. doi:10.1038/jid.2011.463

44. Santaguida MG, Del Duca SC, Virili C, Gargano L, Centanni M. The presence of non-segmental vitiligo modifies intracellular cytokine subsets in patients with chronic lymphocytic thyroiditis. Int J Immunopathol Pharmacol (2010) 23:1203-9. doi:10.1177/039463201002300424

45. Wang CQ, Cruz-Inigo AE, Fuentes-Duculan J, Moussai D, Gulati N, SullivanWhalen M, et al. Th17 cells and activated dendritic cells are increased in vitiligo lesions. PLoS One (2011) 6:e18907. doi:10.1371/journal.pone.0018907

46. Kotobuki Y, Tanemura A, Yang L, Itoi S, Wataya-Kaneda M, Murota H, et al. Dysregulation of melanocyte function by Th17-related cytokines: significance of Th17 cell infiltration in autoimmune vitiligo vulgaris. Pigment Cell Melanoma Res (2012) 25:219-30. doi:10.1111/j.1755-148X.2011.00945.x

47. Dwivedi M, Kemp EH, Laddha NC, Mansuri MS, Weetman AP, Begum R. Regulatory $\mathrm{T}$ cells in vitiligo: implications for pathogenesis and therapeutics. Autoimmun Rev (2015) 14:49-56. doi:10.1016/j.autrev.2014.10.002

48. Belleudi F, Purpura V, Scrofani C, Persechino F, Leone L, Torrisi MR. Expression and signaling of the tyrosine kinase FGFR2b/KGFR regulates phagocytosis and melanosome uptake in human keratinocytes. FASEB $J$ (2011) 25:170-81. doi:10.1096/ff.10-162156

49. Van Den Bossche K, Naeyaert JM, Lambert J. The quest for the mechanism of melanin transfer. Traffic (2006) 7:1-10. doi:10.1111/j.1600-0854.2006.00425.x

50. Purpura V, Persechino F, Belleudi F, Scrofani C, Raffa S, Persechino S, et al. Decreased expression of KGF/FGF7 and its receptor in pathological hypopigmentation. J Cell Mol Med (2014) 18:2553-7. doi:10.1111/jcmm.12411

51. Cutolo M. Autoimmune polyendocrine syndromes. Autoimmun Rev (2014) 13:85-9. doi:10.1016/j.autrev.2013.07.006

52. Cunliffe WJ, Hall R, Newell DJ, Stevenson CJ. Vitiligo, thyroid disease and autoimmunity. Br J Dermatol (1968) 80:135-9. doi:10.1111/j.1365-2133.1968. tb12282.x
53. Spritz RA. Modern vitiligo genetics sheds new light on an ancient disease. J Dermatol (2013) 40:310-8. doi:10.1111/1346-8138.12147

54. Gill L, Zarbo A, Isedeh P, Jacobsen G, Lim HW, Hamzavi I. Comorbid autoimmune diseases in patients with vitiligo: a cross-sectional study. J Am Acad Dermatol (2016) 74:295-302. doi:10.1016/j.jaad.2015.08.063

55. Laberge G, Mailloux CM, Gowan K, Holland P, Bennett DC, Fain PR, et al. Early disease onset and increased risk of other autoimmune diseases in familial generalized vitiligo. Pigment Cell Res (2005) 18:300-5. doi:10.1111/j.1600-0749.2005.00242.x

56. Sharma VK, Dawn G, Kumar B. Profile of alopecia areata in Northern India. Int J Dermatol (1996) 35:22-7. doi:10.1111/j.1365-4362.1996.tb01610.x

57. Sharma VK, Kumar B, Dawn G. A clinical study of childhood alopecia areata in Chandigarh, India. Pediatr Dermatol (1996) 13:372-7. doi:10.111 1/j.1525-1470.1996.tb00703.x

58. Sheth VM, Guo Y, Qureshi AA. Comorbidities associated with vitiligo: a ten-year retrospective study. Dermatology (2013) 227:311-5. doi:10.1159/000354607

59. Amerio P, Di Rollo D, Carbone A, Auriemma M, Marra ME, De Remigis P, et al. Polyglandular autoimmune diseases in a dermatological clinical setting: vitiligo-associated autoimmune diseases. Eur J Dermatol (2010) 20:354-8. doi:10.1684/ejd.2009.0939

60. Narita T, Oiso N, Fukai K, Kabashima K, Kawada A, Suzuki T. Generalized vitiligo and associated autoimmune diseases in Japanese patients and their families. Allergol Int (2011) 60:505-8. doi:10.2332/allergolint.11-OA-0303

61. Chu SY, Chen YJ, Tseng WC, Lin MW, Chen TJ, Hwang CY, et al. Comorbidity profiles among patients with alopecia areata: the importance of onset age, a nationwide population-based study. J Am Acad Dermatol (2011) 65:949-56. doi:10.1016/j.jaad.2010.08.032

62. Huang KP, Mullangi S, Guo Y, Qureshi AA. Autoimmune, atopic, and mental health comorbid conditions associated with alopecia areata in the United States. JAMA Dermatol (2013) 149:789-94. doi:10.1001/jamadermatol.2013.3049

63. Zelissen PM, Bast EJ, Croughs RJ. Associated autoimmunity in Addison's disease. J Autoimmun (1995) 8:121-30. doi:10.1006/jaut.1995.0009

64. Dawber RP. Integumentary associations of pernicious anemia. Br J Dermatol (1970) 82:221-3. doi:10.1111/j.1365-2133.1970.tb12428.x

65. Grunnet I, Howitz J, Reymann F, Schwartz M. Vitiligo and pernicious anemia. Arch Dermatol (1970) 101:82-5. doi:10.1001/archderm.1970.04000010084015

66. Fallahi P, Ferrari SM, Ruffilli I, Elia G, Biricotti M, Vita R, et al. The association of other autoimmune diseases in patients with autoimmune thyroiditis: review of the literature and report of a large series of patients. Autoimmun Rev (2016) 15:1125-8. doi:10.1016/j.autrev.2016.09.009

67. Ruggeri RM, Trimarchi F, Giuffrida G, Certo R, Cama E, Campennì A, et al. Autoimmune comorbidities in Hashimoto's thyroiditis: different patterns of association in adulthood and childhood/adolescence. Eur J Endocrinol (2017) 176:133-41. doi:10.1530/EJE-16-0737

68. Saylam Kurtipek G, Cihan FG, Erayman Demirbaş Ş, Ataseven A. The frequency of autoimmune thyroid disease in alopecia areata and vitiligo patients. Biomed Res Int (2015) 2015:435947. doi:10.1155/2015/435947

69. Nejad SB, Qadim HH, Nazeman L, Fadaii R, Goldust M. Frequency of autoimmune diseases in those suffering from vitiligo in comparison with normal population. Pak J Biol Sci (2013) 16:570-4. doi:10.3923/pjbs.2013.570.574

70. Colucci R, Lotti F, Dragoni F, Arunachalam M, Lotti T, Benvenga S, et al. High prevalence of circulating autoantibodies against thyroid hormones in vitiligo and correlation with clinical and historical parameters of patients. Br J Dermatol (2014) 171:786-98. doi:10.1111/bjd.13286

71. Lazzeri L, Colucci R, Cammi A, Dragoni F, Moretti S. Adult onset vitiligo: multivariate analysis suggests the need for a thyroid screening. Biomed Res Int (2016) 2016:8065765. doi:10.1155/2016/8065765

72. Bae JM, Lee JH, Yun JS, Han B, Han TY. Vitiligo and overt thyroid diseases: a nationwide population-based study in Korea. J Am Acad Dermatol (2017) 76:871-8. doi:10.1016/j.jaad.2016.12.034

73. Dash R, Mohapatra A, Manjunathswamy BS. Anti-thyroid peroxidase antibody in vitiligo: a prevalence study. J Thyroid Res (2015) 2015:192736. doi:10.1155/2015/192736

74. Vrijman C, Kroon MW, Limpens J, Leeflang MM, Luiten RM, van der Veen JP, et al. The prevalence of thyroid disease in patients with vitiligo: a systematic review. Br J Dermatol (2012) 167:1224-35. doi:10.1111/j.1365-2133.2012. 11198.x

75. Colucci R, Lotti F, Arunachalam M, Lotti T, Dragoni F, Benvenga S, et al. Correlation of serum thyroid hormones autoantibodies with self-reported 
exposure to thyroid disruptors in a group of nonsegmental vitiligo patients. Arch Environ Contam Toxicol (2015) 69:181-90. doi:10.1007/s00244-015-0138-7

76. Shong YK, Kim JA. Vitiligo in autoimmune thyroid disease. Thyroidology (1991) 3:89-91.

77. Artantaş S, Gül U, Kiliç A, Güler S. Skin findings in thyroid diseases. Eur J Intern Med (2009) 20:158-61. doi:10.1016/j.ejim.2007.09.021

78. Liu M, Murphy E, Amerson EH. Rethinking screening for thyroid autoimmunity in vitiligo. J Am Acad Dermatol (2016) 75:1278-80. doi:10.1016/j. jaad.2016.04.029

79. Czajkowski R, Męcińska-Jundziłł K. Current aspects of vitiligo genetics. Postepy Dermatol Alergol (2014) 31:247-55. doi:10.5114/pdia.2014.43497

80. Weetman AP. The genetics of autoimmune thyroid disease. Horm Metab Res (2009) 41:421-5. doi:10.1055/s-0029-1214415

81. Spritz RA. Shared genetic relationships underlying generalized vitiligo and autoimmune thyroid disease. Thyroid (2010) 20:745-54. doi:10.1089/ thy.2010.1643

82. Jin Y, Birlea SA, Fain PR, Ferrara TM, Ben S, Riccardi SL, et al. Genome-wide association analyses identify 13 new susceptibility loci for generalized vitiligo. Nat Genet (2012) 44:676-80. doi:10.1038/ng.2272

83. Simmonds MJ. GWAS in autoimmune thyroid disease: redefining our understanding of pathogenesis. Nat Rev Endocrinol (2013) 9:277-87. doi:10.1038/ nrendo.2013.56

84. Medici M, Porcu E, Pistis G, Teumer A, Brown SJ, Jensen RA, et al. Identification of novel genetic loci associated with thyroid peroxidase antibodies and clinical thyroid disease. PLoS Genet (2014) 10:e1004123. doi:10.1371/journal. pgen.1004123

85. Alkhateeb A, Jarun Y, Tashtoush R. Polymorphisms in NLRP1 gene and susceptibility to autoimmune thyroid disease. Autoimmunity (2013) 46:215-21. doi:10.3109/08916934.2013.768617

86. Alkhateeb A, Stetler GL, Old W, Talbert J, Uhlhorn C, Taylor M, et al. Mapping of an autoimmunity susceptibility locus (AIS1) to chromosome 1p31.3-p32.2. Hum Mol Genet (2002) 11:661-7. doi:10.1093/hmg/11.6.661

87. Fain PR, Gowan K, LaBerge GS, Alkhateeb A, Stetler GL, Talbert J, et al. A genomewide screen for generalized vitiligo: confirmation of AIS1 on chromosome 1p31 and evidence for additional susceptibility loci. Am J Hum Genet (2003) 72:1560-4. doi:10.1086/375451

88. Spritz RA, Gowan K, Bennett DC, Fain PR. Novel vitiligo susceptibility loci on chromosomes 7 (AIS2) and 8 (AIS3), confirmation of SLEV1 on chromosome 17, and their roles in an autoimmune diathesis. Am J Hum Genet (2004) 74:188-91. doi:10.1086/381134

89. Schunter JA, Löffler D, Wiesner T, Kovacs P, Badenhoop K, Aust G, et al. A novel FoxD3 variant is associated with vitiligo and elevated thyroid auto-antibodies. J Clin Endocrinol Metab (2015) 100:E1335-42. doi:10.1210/jc.2015-2126

90. Gong Q, Li X, Gong Q2, Zhu W, Song G, Lu Y. Hashimoto's thyroiditis could be secondary to vitiligo: the possibility of antigen crossover and oxidative stress between the two diseases. Arch Dermatol Res (2016) 308:277-81. doi:10.1007/ s00403-016-1641-z

91. Slominski A, Wortsman J, Kohn L, Ain KB, Venkataraman GM, Pisarchik A, et al. Expression of hypothalamic-pituitary-thyroid axis related genes in the human skin. J Invest Dermatol (2002) 119:1449-55. doi:10.1046/j.1523-1747.2002.19617.x

92. Cianfarani F, Baldini E, Cavalli A, Marchioni E, Lembo L, Teson M, et al. TSH receptor and thyroid-specific gene expression in human skin. J Invest Dermatol (2010) 130:93-101. doi:10.1038/jid.2009.180

Conflict of Interest Statement: The authors declare that the research was conducted in the absence of any commercial or financial relationships that could be construed as a potential conflict of interest.

The reviewers SF and IR and handling editor declared their shared affiliation.

Copyright (c) 2017 Baldini, Odorisio, Sorrenti, Catania, Tartaglia, Carbotta, Pironi, Rendina, D'Armiento, Persechino and Ulisse. This is an open-access article distributed under the terms of the Creative Commons Attribution License (CC BY). The use, distribution or reproduction in other forums is permitted, provided the original author(s) or licensor are credited and that the original publication in this journal is cited, in accordance with accepted academic practice. No use, distribution or reproduction is permitted which does not comply with these terms. 